\title{
Investigation of Solid Dispersion of Atorvastatin Calcium in Polyethylene Glycol 6000 and Polyvinylpyrrolidone
}

\author{
Liandong $\mathrm{Hu}^{1,2 *}$, Deliang $\mathrm{Gu}^{1,2}$, Qiaofeng $\mathrm{Hu}^{1,2}$, Yanjing $\mathrm{Shi}^{1,2}$ and $\mathrm{Na} \mathrm{Gao}{ }^{1,2}$ \\ ${ }^{1}$ College of Pharmaceutical Sciences, ${ }^{2}$ Key Laboratory of Pharmaceutical Quality Control of Hebei Province, Hebei University, \\ Baoding, China \\ *For correspondence: Email: hbupharm@126.com; Tel: +86-312-5971107; Fax: +86-312-5971107
}

\begin{abstract}
Purpose: To improve the solubility and bioavailability of atorvastatin calcium (ATC), a poorly watersoluble 3-hydroxy 3-methyl glutaryl CoA (HMG-CoA) reductase inhibitor, by a solid dispersion technique using polyethylene glycol 6000 (PEG 6000) or polyvinylpyrrolidone k30 (PVP K30).

Methods: The solid dispersions were characterised by differential scanning calorimetry (DSC), powder $x$-ray diffraction (PXRD) and Fourier transformed infrared (FT-IR) spectroscopy. The dissolution characteristics of the formulations were determined in vitro, while the bioavailability of the solid dispersion and suspension was evaluated in rats.

Results: DSC, PXRD and FT-IR data confirmed the formation of solid dispersion. The dissolution results showed that almost $95 \%$ of ATC in ATC- PVP K30 solid dispersion dissolved in 5 min. The amount of ATC in ATC-PVP K30 SD, ATC-PEG 6000 SD and pure ATC that dissolved in 60 min was 103,85 and $93 \%$, respectively. In addition, in vivo bioavailability studies in rats showed that area under concentration-time curve $(A U C)$ and peak concentration $\left(C_{\max }\right)$ of ATC-PVP K30 solid dispersion was 3.5-fold and 4.9-fold higher than that of the drug in suspension. Time to attain peak concentration ( $\left.T_{\max }\right)$ of ATC-PVP K30 solid dispersion was $0.25 \pm 0.00 h$, which is shorter than $0.83 \pm 0.26 \mathrm{~h}$ for suspension. Conclusion: The results obtained indicates that solid dispersions of ATC made with polyethylene glycol 6000 and polyvinylpyrrolidone K30 are an effective new approach to designing formulations of poorly soluble ATC for greatly enhanced solubility and bioavailability.
\end{abstract}

Keywords: Solid dispersion, Atorvastatin, Polyethylene glycol, Polyvinypyrrolidone K30, Bioavailability, Dissolution

Tropical Journal of Pharmaceutical Research is indexed by Science Citation Index (SciSearch), Scopus, International Pharmaceutical Abstract, Chemical Abstracts, Embase, Index Copernicus, EBSCO, African Index Medicus, JournalSeek, Journal Citation Reports/Science Edition, Directory of Open Access Journals (DOAJ), African Journal Online, Bioline International, Open-J-Gate and Pharmacy Abstracts

\section{INTRODUCTION}

The solubility behavior of drugs remain one of the most challenging aspects of formulation development [1,2]. One of the major challenges of the pharmaceutical industry is related to improving the water solubility of drugs. In recent years, solid dispersions have been widely used to improve the solubility of water-insoluble drugs, enhance the physical and chemical stability, eliminate undesired properties of drugs, and improve the bioavailability [3]. Solid dispersion is a multi-component system whereby a crystalline or amorphous drug is dispersed in an amorphous or semicrystalline polymer matrix [4].

Some compounds such as PEG 6000 and PVP K30 have been reported as carriers. Methods recently used to prepare amorphous solid dispersions include mechanical milling [5], fusion [6], hot melt extrusion [7], spray drying [8], freeze drying [9] and supercritical fluid precipitation [10]. 
Atorvastatin, as a synthetic lipid-lowering agent, is an inhibitor of 3-hydroxy-3-methyl-glutarylcoenzyme A (HMG-CoA) reductase which catalyzes the conversion of HMG-CoA to mevalonate, an early rate-limiting step in cholesterol biosynthesis [11]. Atorvastatin calcium is [R- (R', R')]-2- (4- fluorophenyl)- beta, delta- dihydroxy- 5- (1- methylethyl)- 3- phenyl4- [(phenylamino) carbonyl]- IH- pyrrole- 1heptanoic acid, calcium salt (2:1) trihydrate. It is a white to off-white crystalline powder; very slightly soluble in water and $\mathrm{pH} 7.4$ buffer (insoluble in aqueous solutions of $\leq \mathrm{pH} 4$ ). ATC is rapidly absorbed after oral administration, with time to reach peak concentrations ( $T$ max) within $1-2 \mathrm{~h}$ but possess poor oral bioavailability (12 $\%$ ) [12]. The poor oral bioavailability is attributed to its low aqueous solubility, crystalline nature, and high hepatic first-pass metabolism [13,14]. Furthermore, the bioavailability of ATC is highly variable due to its instability in the acidic milieu of the stomach [15]. Poor oral bioavailability of ATC results in administration of high doses and engenders dose related undesirable adverse effects such as liver abnormalities, rhabdomyolysis, arthralgia, and kidney failure. There are many existing factors limiting the successful use of orally administered ATC, including problems with drug formulation due to poor aqueous solubility and more importantly, insufficient and fluctuating bioavailability obtained after oral administration [16].

The objective of this study was to improve the solubility and bioavailability of poorly watersoluble ATC by a solid dispersion technique using PEG 6000 and PVP K30 as polymeric carriers.

\section{EXPERIMENTAL}

\section{Materials}

ATC was obtained from Zhejiang Xin Donggang pharmaceutical co., LTD (Zhejiang, China). PVP K30 was obtained from Tianjin Guangfu Fine Chemical Research Institute (Tianjin, China). PEG 6000 was provided by Tianjin Yongda Chemical Reagent Co., Ltd (Tianjin, China). All other chemicals were of analytical grade, and used without further purification. Distilled water was used throughout the study.

\section{Preparation of solid dispersions}

In solvent melting method, firstly, different amounts of PEG 6000 or PVP K30 such as 5, 7 and $9 \mathrm{~g}$ were separately dissolved in ethanol while $1 \mathrm{~g}$ ATC was dissolved in the solution mentioned above with the ratio of drug to carrier as $1: 5,1: 7,1: 9(\mathrm{w} / \mathrm{w})$. The solvent was removed under reduced pressure in a rotary evaporator at $40{ }^{\circ} \mathrm{C}$. The powder obtained was micronized by grinding in a mortar and the resultant mass was passed through a 100 mesh sieve. The best ratio of PEG 6000 or PVP K30 with ATC was chosen via dissolution tests.

The physical mixture of ATC and polymeric carrier (PEG 6000 or PVP K30) was prepared by mixing ATC and polymeric carrier (1:7 w/w), using a mortar and pestle for $10 \mathrm{~min}$, after the powders of both components had been previously sieved through an sieve $(0.178 \mathrm{~mm})$.

\section{Differential scanning calorimetry (DSC) studies}

DSC thermograms of ATC, PEG 6000, PVP K30, their physical mixture and solid dispersion were measured. DSC measurements were performed on a DSC-60 thermal analyzer (Shimadzu Corporation, Japan) at a heating rate of $10{ }^{\circ} \mathrm{C}$ /min from 30 to $200{ }^{\circ} \mathrm{C}$ under a nitrogen purge gas flow rate of $25 \mathrm{~mL} / \mathrm{min}$. Indium was used to calibrate for the temperature scale and energy. Accurately weighted amounts of samples were placed in perforated aluminum pans.

\section{Powder x-ray diffraction (PXRD) analysis}

Powder $\mathrm{x}$-ray diffraction diagrams were obtained with a Y-2000 Automated X-ray diffractometer (Drigc, China) with $\mathrm{Cu}$ Ka-radiation $(\lambda=1.5406$ $\AA$ ) in the range of $5-45^{\circ}(2 \theta)$ at $30 \mathrm{kV}$ and 20 $\mathrm{mA}$ over a $2 \theta$ range of $5-45^{\circ}$ using a step size of $0.06^{\circ}$ at a scan speed of 1 s/step, and a system of diverging and receiving slides were $1^{\circ}$ and $0.2 \mathrm{~mm}$, respectively.

\section{Fourier-transform infrared spectroscopy (FT- IR)}

FT-IR spectra of samples were recorded with a FT-IR spectrometer-8400S (Shimadzu, Japan) by $\mathrm{KBr}$ disc method in the wave range of $400-$ $4000 \mathrm{~cm}^{-1}$. Twenty scans over the selected wave number range at a resolution of $4.0 \mathrm{~cm}^{-1}$ were averaged for each sample.

\section{Dissolution studies}

Dissolution studies were carried out using a ZRS-8G dissolution apparatus (Haiyida, China). The apparatus was operated at the paddle rotation speed of $50 \mathrm{rpm}$ in $900 \mathrm{ml}$ distilled water at $37 \pm 0.5^{\circ} \mathrm{C}$. The samples were withdrawn at 5 , $15,30,45$ and $60 \mathrm{~min}$ and filtered through a 
membrane filter (pore size $0.45 \mu \mathrm{m}$ ). The withdrawn volume was replenished immediately with an equal volume of corresponding dissolution medium to maintain sink conditions. The samples were measured by UV/VIS spectrophotometer at $241 \mathrm{~nm}$.

\section{High performance liquid chromatography (HPLC) studies}

The samples were determined using a Shimadzu LC-20AT HPLC (Shimadzu, Kyoto, Japan) equipped with a C-18 chromatographic column (5 $\mu \mathrm{m}, 250 \mathrm{~mm} \times 4.6 \mathrm{~mm})$. The mobile phase was composed of acetonitrile/water $(60: 40 \mathrm{v} / \mathrm{v})$ to which $0.05 \%$ glacial acetic acid was added. The flow rate was $1.0 \mathrm{~mL} / \mathrm{min}$. The wavelength was set at $241 \mathrm{~nm}$.

\section{In vivo pharmacokinetic studies}

The animal studies protocol for the pharmacokinetic aspects of this work was reviewed and approved by the Institutional Animal Ethics Committee of Hebei Medical University (Proposal no. SCXK2008-1-003), and the International Guidelines for Handling of Laboratory Animals [17] were followed in this study.

Twelve Sprague-Dawley rats $(210 \pm 10 \mathrm{~g}$ body weight) were fasted for $12 \mathrm{~h}$ prior to the beginning of the study. The rats were divided into two groups with each group containing 6 rats. The rats were given ATC-suspension (750 $\mathrm{mg} / \mathrm{kg}$ ) and solid dispersion (75 mg/kg). ATCsuspension was ATC dispersing in $0.4 \% \mathrm{CMC}$ $\mathrm{Na}$ before administration. Blood samples $(0.5$ $\mathrm{mL}$ ) were collected in heparin-wetted tubes at 0 , $0.25,0.5,1,2,4,6,8$ and $12 \mathrm{~h}$. Plasma samples were obtained by vortexed blood samples for 5 $\mathrm{min}$ and centrifuged at $4000 \mathrm{rpm}$ for $15 \mathrm{~min}$ to get the supernatant. The plasma samples were stored at $-20{ }^{\circ} \mathrm{C}$ before analyzing by HPLC method.

Microsoft Office Excel 2003 software was used to analyze the pharmacokinetic parameters. $\mathrm{K}$ was estimated by the linear regression of Log C/time profile (Log $\mathrm{C}$ is the log-normal transformed plasma concentration). The terminal elimination half-life $\left(T_{1 / 2}\right)$ was calculated by $T_{1 / 2}=0.693 / \mathrm{K}$. Peak observed concentrations $\left(\mathrm{C}_{\max }\right)$ of drug and times to reach peak plasma concentration ( $\left.T_{\max }\right)$ were determined from the individual plasma concentration-time curves. The total area under the concentration-time curve (AUC) was calculated by the trapezoids method. The area from time zero to infinity was calculated by $\mathrm{AUC}_{0}$ $\infty=\mathrm{AUC}_{0-\mathrm{t}}+\mathrm{Ct} / \mathrm{K}$. AUMC was the area under the first moment of the plasma concentration-time curve, calculated by AUMC ${ }_{0-\infty}=\mathrm{AUMC}_{0-\mathrm{t}}+\mathrm{Ct}$ /K. Mean residence time was MRT (MRT= AUMC/ AUC).

\section{Statistical analysis}

Data were processed using Microsoft Excel 2003 software and presented as mean \pm SD. Differences between data were considered significant at $p<0.05$ using Student's t-test.

\section{RESULTS}

\section{Thermal characteristics}

The DSC results are shown in Fig 1. DSC curve of pure ATC showed an endotherm of water loss in the temperature range of $90-130{ }^{\circ} \mathrm{C}$ and a sharp endotherm at $164{ }^{\circ} \mathrm{C}$ indicate the melting point of ATC. DSC curve of PEG 6000 showed a characteristic peak at $61{ }^{\circ} \mathrm{C}$. In the physical mixture, the endothermic peaks in the DSC curves based on ATC were observed. The characteristic peaks of ATC almost disappeared in the solid dispersion, which indicated ATC's dissolution in PEG 6000 and a crystalline change. Based on these results, it appeared that the solid dispersion was formed. Unlike the curve of PEG 6000, PVP K30 showed an entirely different behavior in melting process. From Fig. 1, we could find that PVP K30 had a broad endothermic of water loss in the temperature range of $60-120^{\circ} \mathrm{C}$. And its melting point was higher than that of PEG 6000. DSC curve of physical mixture showed a small characteristic peak of ATC at $164{ }^{\circ} \mathrm{C}$, which indicated existing of the crystal form of ATC. The absence of ATC peaks in case of solid dispersions suggested molecular dispersion of the drug in PVP K30. That showed ATC's dissolution in PVP K30.

\section{X-ray diffraction}

Since it was not possible to identify the solid dispersion by DSC, PXRD was used to identify the formation of solid dispersion. The PXRD diagrams of ATC, PEG 6000, their physical mixture and solid dispersion are shown in Figure 2. The diffraction pattern of pure drug showed characteristic high-intensity peaks at 8.9, 9.26, $10.04,10.34,11.66,11.96,16.82,19.22,21.38$, $22.46,23.06$, and 23.48 , which indicates that the drug is present in the crystalline form that is also confirmed by DSC results. PEG 6000 showed two characteristic peaks at 19.22 and 23.36. Physical mixture's pattern showed the characteristic peaks of ATC with low intensity, which indicated the presence of ATC in 


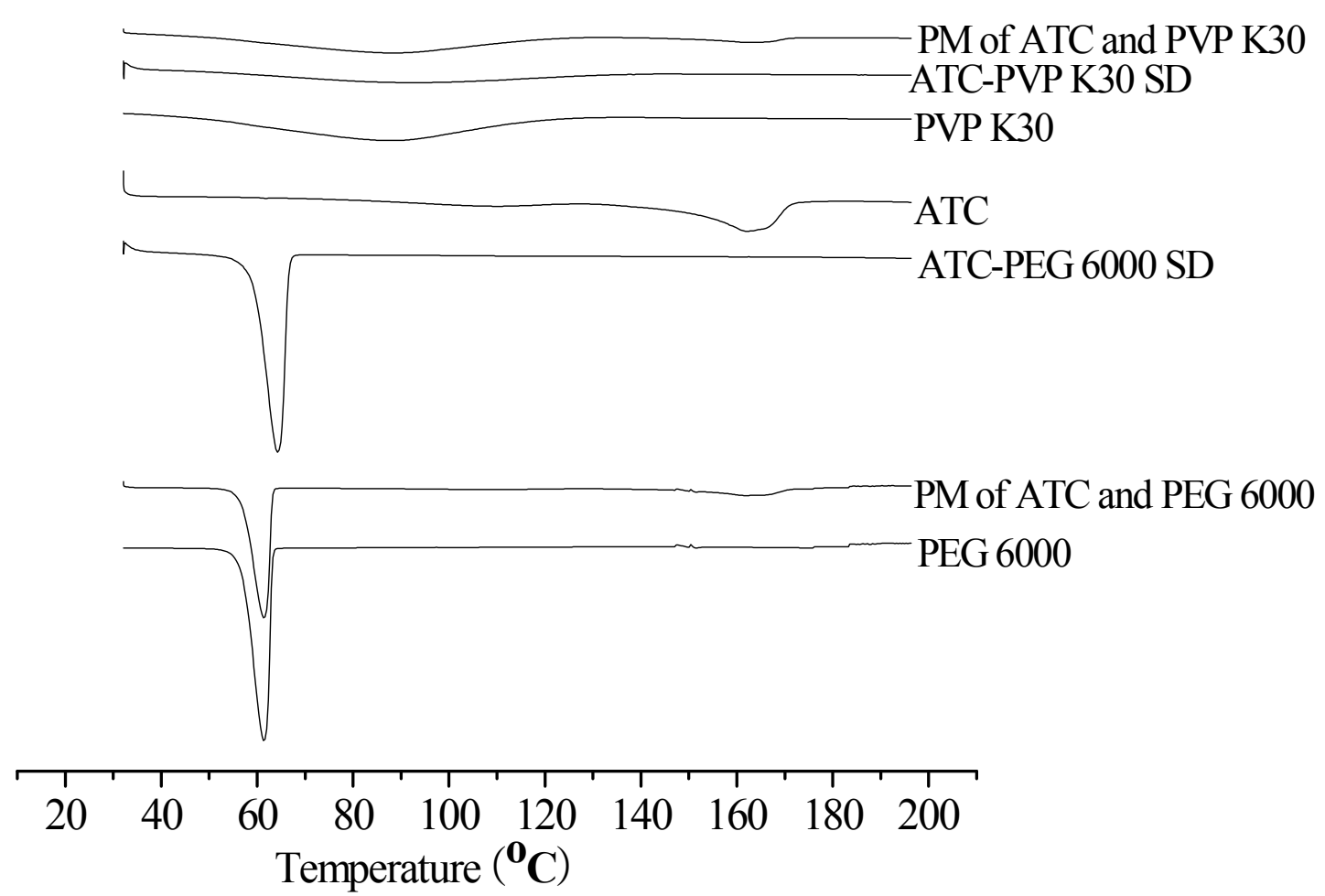

Fig 1: DSC thermograms of ATC, PEG 6000, PVP K30, their physical mixture and solid dispersion

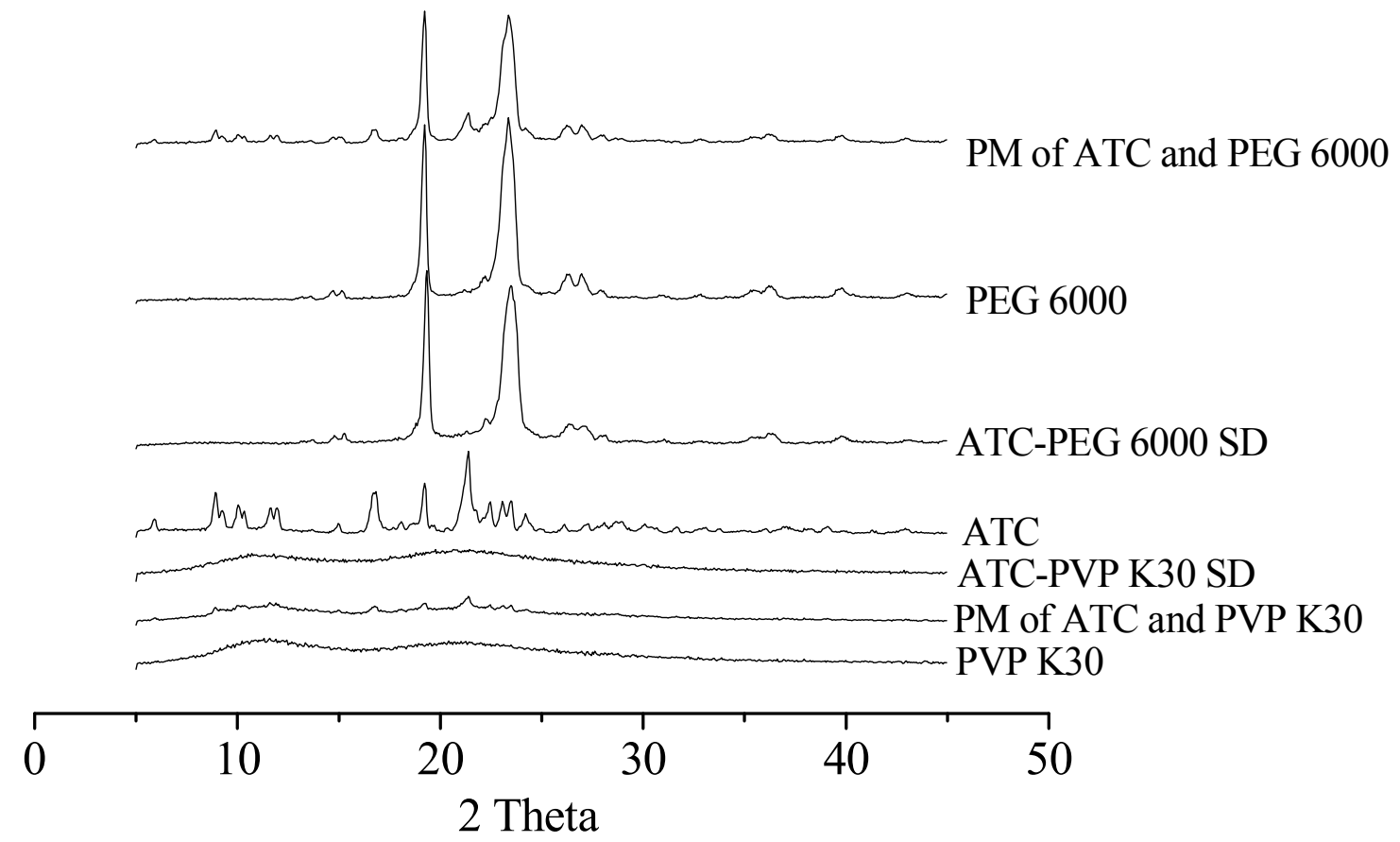

Fig 2: X-ray diffractograms of ATC, PEG 6000, PVP K30, their physical mixture and solid dispersion 
crystalline state. In contrast, the characteristic peaks of ATC could not be observed in solid dispersion's pattern, and solid dispersion's pattern was similar with that of PEG 6000 . These results were in accord with previous DSC results, confirming that inclusion complex formed. Figure 2 also showed the diffraction pattern of ATC, PVP K30, their physical mixture and solid dispersion. It was observed that the diffraction pattern of PVP K30 had two broad peaks in the range of $5^{\circ}-15^{\circ}$ and $15^{\circ}-25^{\circ}(2 \theta)$, confirming its amorphous characteristic. In the case of solid dispersion, no characteristic ATC peaks were observed. However, most characteristic peaks of ATC appeared in physical mixture with lower intensity. The results indicated the formation of ATC-PVP K30 solid dispersion, which was in agreement with $\mathrm{DSC}$ results.

\section{FT-IR spectra}

FT-IR was shown to support the evidence for the solid dispersion formation between ATC and carriers (PEG 6000 or PVP K30). FT-IR spectra of the pure drug, PEG 6000, PVP K30, their physical mixture and solid dispersion are shown in Figure 3. Characteristic peaks of ATC between 3700 and $3000 \mathrm{~cm}^{-1}$, specifically at 3670,3566 , 3365, 3246, 3055, 2887, 2360, 1650 and 1579 $\mathrm{cm}^{-1}$. The peak at $3670 \mathrm{~cm}^{-1}$ indicated free $\mathrm{O}-\mathrm{H}$ stretching, while the absorbance at $3365 \mathrm{~cm}^{-1}$ and from 1700 to $1400 \mathrm{~cm}^{-1}$ indicated the stretching vibrations of $\mathrm{N}-\mathrm{H}$ and $\mathrm{C}-\mathrm{C}$ bond of aromatic ring. Other peaks at $3246 \mathrm{~cm}^{-1}$ and $3055 \mathrm{~cm}^{-1}$ represent asymmetrical $\mathrm{O}-\mathrm{H}$ stretching and symmetrical $\mathrm{O}-\mathrm{H}$ stretching. PEG 6000 showed a $\mathrm{C}-\mathrm{H}$ stretching $2889 \mathrm{~cm}^{-1}$ and a $\mathrm{C}-\mathrm{O}$ stretching $1109 \mathrm{~cm}^{-1}$. The spectra of physical mixture had almost every characteristic peak of ATC and PEG 6000. While that of solid dispersion showed no ATC characteristic peaks. The spectrum of PVP K30 exhibited important bands at $2952 \mathrm{~cm}^{-1}$ (C-H stretching) and 1676 $\mathrm{cm}^{-1}(\mathrm{C}=\mathrm{O})$. A broad band was visible from 3700 $\mathrm{cm}^{-1}$ to $3200 \mathrm{~cm}^{-1}$, which had relation to the presence of water, corresponding to the broad endotherm in DSC. The physical mixture showed ATC's characteristic peak at $3365 \mathrm{~cm}^{-1}$ that was smaller than that of ATC. It indicated the existence of ATC in physical mixture. Meanwhile, the spectrum of solid dispersion looked like that of PVP K30. And no additional peak was found, indicating no chemical reactions between ATC and carriers. All the results of DSC, PXRD and FT-IR showed the formations of solid dispersions.

\section{Dissolution}

The dissolution rate profiles are shown in Figure 4. Dissolution patterns of ATC and ATC-PEG 6000 were slower than that of ATC-PVP K30 at the same ratio but the pattern of ATC-PVP K30 $(1: 7 \mathrm{w} / \mathrm{w})$ was similar to that of ATC- PVP K30 $(1: 9 w / w)$

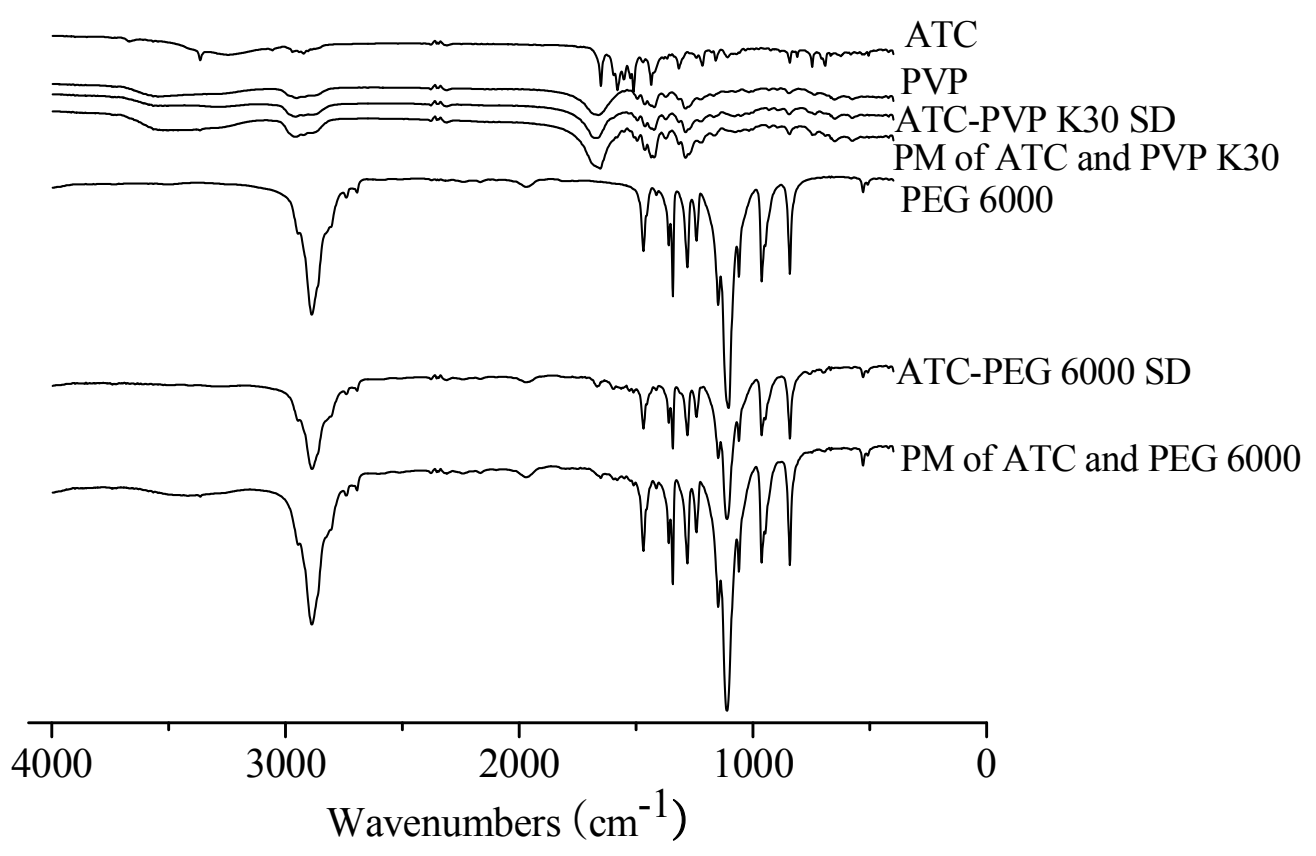

Fig 3: The spectra of ATC, PEG 6000, PVP K30, their physical mixture and solid dispersion 


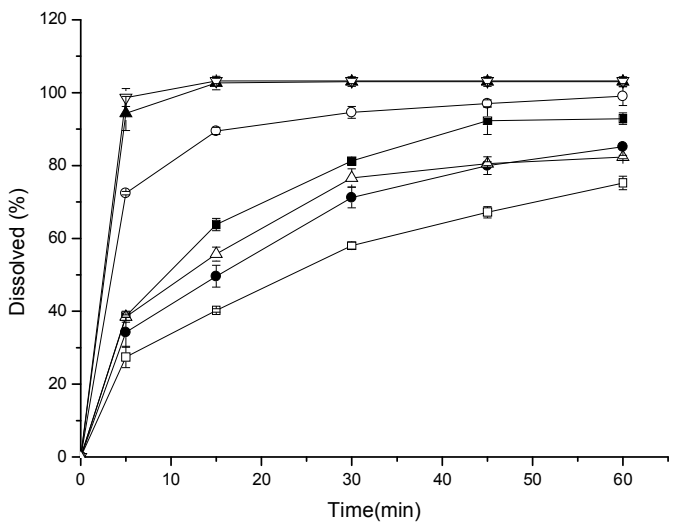

Fig 4: The release rate profiles ( $\square=$ ATC-PEG 6000 SD $(1: 5 \mathrm{w} / \mathrm{w}), \bullet=$ ATC-PEG $6000(1: 7 \mathrm{w} / \mathrm{w}) ; \triangle=$ ATC-PEG 6000 SD $(1: 9 \mathrm{w} / \mathrm{w})$, = = ATC, o = ATC-PVP K30 SD $(1: 5 \mathrm{w} / \mathrm{w}), \boldsymbol{\Delta}=$ ATC-PVP K30 SD $(1: 7 \mathrm{w} / \mathrm{w})$, $\nabla=$ ATC-PVP K30 SD $(1: 9 \mathrm{w} / \mathrm{w}))$. Data are expressed as mean $\pm S D(n=6)$

but much faster than that of ATC- PVP K30 (1:5 $w / w)$. The dissolution patterns of ATC-PEG 6000 also followed the same trend. Hence, the ratio $1: 7$ was selected. Almost $95 \%$ of the ATC-PVP
K30 (1:7 w/w) dissolved in $5 \mathrm{~min}$. It was entirely dissolved in $15 \mathrm{~min}$ and there were no extra dissolutions in the next three points. Hence, ATC- PVP K30 solid dispersion (1:7 w/w) was used for in vivo study.

\section{Pharmacokinetics}

Figure 5 shows the plasma levels of ATC in two formulations (ATC-suspension and ATC solid dispersion with PVP K30) after oral administration. The oral pharmacokinetic parameters are shown in Table 1. Values of $\mathrm{C}_{\max }$ and $\mathrm{AUC}_{0-\infty}$ of $\mathrm{ATC}$-suspension were smaller than those of the solid dispersion systems and $\mathrm{T}_{\text {max }}$ of ATC-suspension was much longer than that of the solid dispersion systems. From Figure 5 and Table 1 we could see that the solid dispersion system with PVP K30 as carrier would be useful to deliver poorly water-soluble ATC, for it had better effect in enhancing bioavailability than that of suspension in equal content.

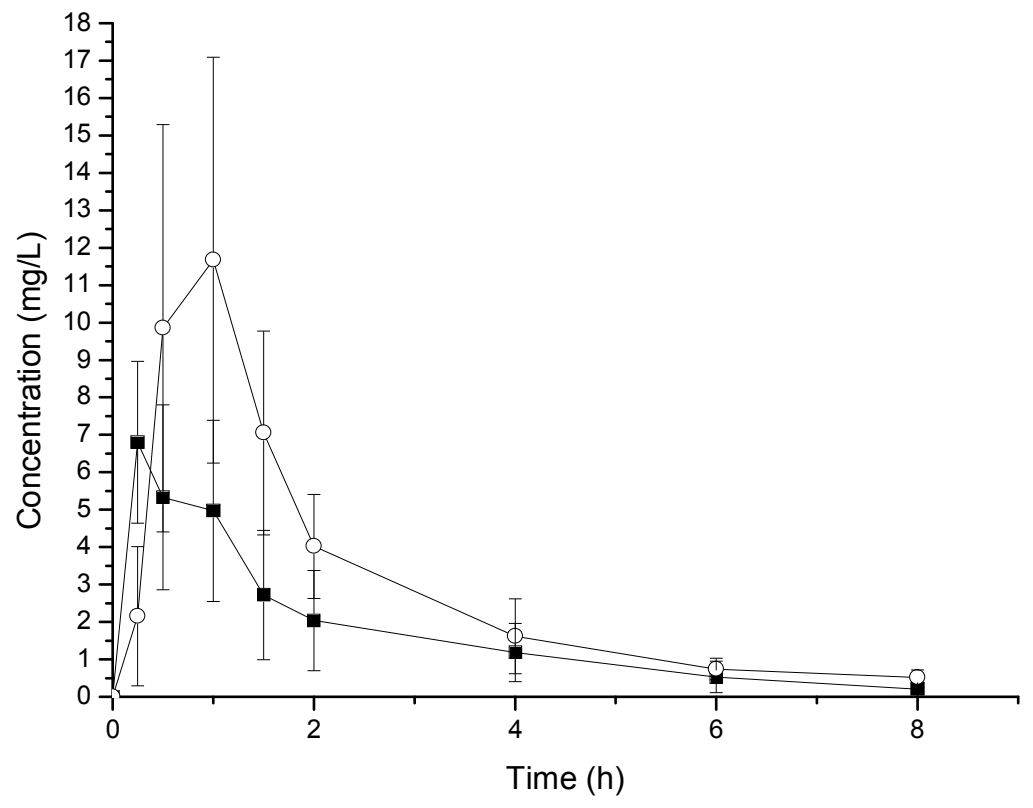

Fig 5: Mean plasma concentration \pm SD versus time curves $(o=$ ATC-suspension, $\mathbf{m}=$ ATC solid dispersion in PVP K30)

Table 1: Pharmacokinetic data for the formulations (mean $\pm S D, n=6$ )

\begin{tabular}{lcccc}
\hline Parameter & $\mathbf{T}_{\max }(\mathbf{h})$ & $\mathbf{C}_{\max }(\mathbf{m g} / \mathbf{L})$ & $\mathbf{A U C}_{0_{-\infty}}(\mathbf{h} \mathbf{~ m g} / \mathbf{L})$ & MRT(h) \\
\hline $\begin{array}{l}\text { ATC-suspension } \\
\text { ATC solid dispersion }\end{array}$ & $0.83 \pm 0.26$ & $14.74 \pm 4.52$ & $40.51 \pm 10.39$ & $3.87 \pm 0.72$ \\
with PVP K30 & $0.25 \pm 0.00$ & $6.80 \pm 2.06$ & $14.05 \pm 6.13$ & $2.72 \pm 0.80$ \\
\hline
\end{tabular}

$T_{\max }=$ peak time; $C_{\max }=$ peak concentration; $A U C_{0-\infty}=$ area under concentration-time curve; $M R T=$ mean retention time 


\section{DISCUSSION}

This study showed improvement in the dissolution rate and bioavailability of ATC in ATC-PVP K30 solid dispersion. This may be due to the character of PVP K30. Since PVP K30 has high viscosity, it would reduce re-aggregation and agglomeration of ATC. In addition, the hydrophilic character of PVP K30 might have improved water penetration. The release rate of ATC-PEG 6000 was lower than that of ATC. This may be a drug-controlled dissolution mechanism. In this case dissolution into the polymer diffusion layer was comparatively slow and the drug was released as solid particles. Consequently the dissolution was not associated with the polymer but instead was dominated by the properties (size, physical form, etc.) of the ATC [4].

The bioavailability of ATC was increased by solid dispersion. Previous studies also showed an increased oral bioavailability of some other drugs by using solid dispersion [18-20]. The increased bioavailability may be due to the following reasons: First, ATC is a BCS Class II drug that has a high permeability but low solubility. Hence, the absorption of ATC was related to the dissolution rate of the formulation. Second, due to the interactions of hydrogen bonding or complex and the increasing in the viscosity of PVP K30, the formation and growth of the drug was suppressed and the drug became amorphous form. Third, since ATC dispersed in solid dispersion has a large surface area, it increased the interfacial area of contact between the drug particles and dissolution medium, leading to improved dissolution and bioavailability.

\section{CONCLUSION}

PVP K30 is the more suitable carrier for preparing ATC solid dispersion tablet with the optimum ratio of ATC to PVP K30 of $1: 7 \mathrm{w} / \mathrm{w}$. The solid dispersion obtained demonstrates better bioavailability than ATC suspension, thus confirming that the solid dispersion would improve the efficacy of the poor water-soluble drug. Thus, solid dispersion is a promising approach to enhancing the bioavailability of ATC.

\section{ACKNOWLEDGEMENT}

This work was supported by the Talent Introduction Program of Hebei University (no. y2005064) and by a grant of the Medical and Engineering Science Research Center of Hebei University (no. BM201109).

\section{REFERENCES}

1. Serajuddin AT. Solid dispersion of poorly water soluble drugs: early promises, subsequent problems, and recent breakthroughs. J Pharm Sci 2000; 88: 10581066.

2. Lin C. Enhancement of dissolution rate of rofecoxib using solid dispersion with urea. Drug Dev Res 2004; 63: 181-189.

3. Chiou WL, Riegelman S. Increased dissolution rates of water-insoluble cardiac glycosides and steroids via solid dispersions in polyethylene glycol 6000. J Pharm Sci 1971; 73: 1281-1303.

4. Craig DQ. The mechanisms of drug release from solid dispersions in water- soluble polymers. Int $J$ Pharm 2002; 231: 131-144.

5. Peltonen L, Hirvonen J. Pharmaceutical nanocrystals by nanomilling: critical process parameters, particle fracturing and stabilization methods. J. Pharm. Pharmacol 2010; 62: 1569-1579.

6. DiNunzio JC, Brough C, Hughey JR, Miller DA, Williams RO 3rd, McGinity JW. Fusion production of solid dispersions containing a heat-sensitive active ingredient by hot melt extrusion and Kinetisol dispersing. Eur. J. Pharm. Biopharm 2010; 74: 340351.

7. Lakshman JP, Cao Y, Kowalski J, Serajuddin AT. Application of melt extrusion in the development of a physically and chemically stable high- energy amorphous solid dispersion of a poorly water-soluble drug. Mol. Pharm 2008; 5: 994-1002.

8. Alhalaweh A, Andersson S, Velaga SP. Preparation of zolmitriptan-chitosan microparticles by spray drying for nasal delivery. Eur. J. Pharm. Sci 2009; 38: 206214.

9. Yang W, Tam J, Miller DA, Zhou J, McConville JT, Johnston KP, Williams RO. 3rd. High bioavailability from nebulized itraconazole nanoparticle dispersions with biocompatible stabilizers. Int. J. Pharm 2008; 361: 177-188.

10. Bouchard A, Jovanović N, Hofland GW, Jiskoot W, Mendes E, Crommelin DJ, Witkamp GJ. Supercritical fluid drying of carbohydrates: selection of suitable excipients and process conditions. Eur. J. Pharm. Biopharm 2008; 68: 781- 794.

11. Kim JS, Kim MS, Park HJ, Jin SJ, Lee S, Hwang SJ. Physicochemical properties and oral bioavailability of amorphous atorvastatin hemi-calcium using spraydrying and SAS process. Int J Pharm 2008; 359: 211219.

12. Corsini A, Bellosta $S$, Baetta R, Fumagalli R, Paoletti $R$, Bernini F. New insights into the pharmacodynamics and pharmacokinetic properties of statins. Pharmacology Ther 1999; 84: 413-428.

13. Cilla $D D J r$, Whitfield LR, Gibson DM, Sedman AJ, Posvar EL. Multiple-dose pharmacokinetics, pharmacodynamics, and safety of atorvastatin, an 
inhibitor of HMG-CoA reductase, in health subjects. Clin Pharmacol Ther 1996; 60: 687-695.

14. Lennernäs $H$. Clinical pharmacokinetics of atorvastatin. Clin Pharmacokinet 2003; 42: 1141-1160.

15. Shah SJ, Waters DD, Barter P, Kastelein JJ, Shepherd J, Wenger NK, DeMicco DA, Breazna A, LaRosa JC. Intensive lipid-lowering with atorvastatin for secondary prevention in patients after coronary artery bypass surge. J Am Coll Cardiol 2008; 51: 19381943.

16. Kim MS, Jin SJ, Kim JS, Park HJ, Song HS, Neubert RH, Hwang SJ. Preparation, characterization and in vivo evaluation of amorphous atorvastatin calcium nanoparticles using supercritical antisolvent (SAS) process. Eur J Pharm Biopharm 2008; 69: 454-465.
17. Derrell C. Guide for the care and use of laboratory animals. Institute of Laboratory Animal Resources. Washington: DC, National Academy Press; 1996.

18. Biswal S, Sahoo J, Murthy PN. Physicochemical Properties of Solid Dispersions of Gliclazide in Polyvinylpyrrolidone K90. AAPS PharmSciTech 2009; 10: 329-334.

19. Kim EJ, Chun MK, Jang JS, Lee IH, Lee KR, Choi HK. Preparation of a solid dispersion of felodipine using a solvent wetting method. Eur J Pharm Biopharm 2006; 64: 200-205.

20. Vijaya Kumar SG, Mishra DN. Preparation, Characterization and in vitro dissolution studies of solid dispersion of meloxicam with PEG 6000. The Pharmaceutical Society of Japan 2006; 26: 657-664. 